\title{
BMJ Open Malnutrition, nutritional interventions and clinical outcomes of patients with acute small bowel obstruction: results from a national, multicentre, prospective audit
}

To cite: Lee MJ, Sayers AE, Drake TM, et al. Malnutrition, nutritional interventions and clinical outcomes of patients with acute small bowel obstruction: results from a national, multicentre, prospective audit. BMJ Open 2019;9:e29235. doi:10.1136/ bmjopen-2019-029235

- Prepublication history and additional material for this paper are available online. To view these files, please visit the journal online (http://dx.doi org/10.1136/bmjopen-2019029235).

Findings from this study have been presented in part at the Association of Coloproctology of Great Britain and Ireland, Association of Surgeons of Great Britain and Ireland and British Society for Gastroenterology 2018 meetings. Additional presentations have been made at the World Society of Emergency Surgery 2018 meeting, and the British Association for Parenteral and Enteral Nutrition and British Association for Surgical Oncology 2017 meetings.

Received 21 January 2019 Revised 5 June 2019 Accepted 13 June 2019

Check for updates

(C) Author(s) (or their employer(s)) 2019. Re-use permitted under CC BY-NC. No commercial re-use. See rights and permissions. Published by BMJ.

For numbered affiliations see end of article.

Correspondence to

Matthew James Lee; m.j.lee@sheffield.ac.uk

\begin{abstract}
Matthew James Lee, ${ }^{\circ 1}$ Adele E Sayers, ${ }^{2}$ Thomas M Drake, ${ }^{3}$ Pritam Singh, ${ }^{4}$ Mike Bradburn, ${ }^{5}$ Timothy R Wilson, ${ }^{6}$ Aravinth Murugananthan, ${ }^{7}$ Ciaran J Walsh, ${ }^{8}$ Nicola S Fearnhead, ${ }^{9}$ on Behalf of NASBO Steering Group and NASBO Collaborators
\end{abstract}

\section{ABSTRACT}

Objective The aim of this study was to assess the nutritional status of patients presenting with small bowel obstruction (SBO), along with associated nutritional interventions and clinical outcomes.

Design Prospective cohort study.

Setting 131 UK hospitals with acute surgical services.

Participants 2069 adult patients with a diagnosis of SBO were included in this study. The mean age was 67.0 years and $54.7 \%$ were female.

Primary and secondary outcome measures Primary outcome was in-hospital mortality. Secondary outcomes recorded included: major complications (composite of inhospital mortality, reoperation, unplanned intensive care admission and 30-day readmission), complications arising from surgery (anastomotic leak, wound dehiscence), infection (pneumonia, surgical site infection, intraabdominal infection, urinary tract infection, venous catheter infection), cardiac complications, venous thromboembolism and delirium.

Results Postoperative adhesions were the most common cause of SBO (49.1\%). Early surgery ( $<24$ hours postadmission) took place in $30.0 \%$ of patients, $22.0 \%$ underwent delayed operation and $47.9 \%$ were managed non-operatively. Malnutrition as stratified by Nutritional Risk Index was common, with $35.7 \%$ at moderate risk and $5.7 \%$ at severe risk of malnutrition. Dietitian review occurred in just $36.4 \%$ and $55.9 \%$ of the moderate and severe risk groups. In the low risk group, $30.3 \%$ received nutritional intervention compared with $40.7 \%$ in moderate risk group and $62.7 \%$ in severe risk group. In comparison to the low risk group, patients who were at severe or moderate risk of malnutrition had 4.2 and 2.4 times higher unadjusted risk of in-hospital mortality, respectively. Propensity-matched analysis found no difference in outcomes based on use or timing of parenteral nutrition. Conclusions Malnutrition on admission is associated with worse outcomes in patients with SBO, and marked variation in management of malnutrition was observed. Future trials should focus on identifying effective and costeffective nutritional interventions in SBO.

\section{Strengths and limitations of this study}

This national prospective cohort study focusses on contemporary management of patients admitted to secondary care with acute small bowel obstruction, demonstrates high rates of malnutrition in this patient population and highlights wide variation in use of nutritional interventions.

- Rigorous data validation ensures high-quality assurance for the data presented.

- The data presented is observational in nature, so only association can be assessed.

- Nutritional status is inferred from data collected at baseline and does not necessarily reflect dynamic changes or ongoing reassessment during hospital admission.

- Malnutrition has been assessed using two methods: with clinical judgement for most participants during data collection phase, and then using a post hoc Nutritional Risk Index during analysis to allow robust assessment and comparisons.

\section{BACKGROUND}

Small bowel obstruction (SBO) is a significant health burden. There are approximately 17500 admissions to English hospitals and upwards of 300000 admissions to US hospitals each year, ${ }^{1-4}$ and is associated with high levels of morbidity and mortality. ${ }^{5}$ Patients with SBO may also be considered to have acute intestinal failure, which is defined by the European Society of Coloproctology as 'the reduction of gut function below the minimum necessary for the absorption of macronutrients and/ or fluid and electrolytes, such that intravenous supplementation is required to maintain health and/or growth. ${ }^{6}$ Depending on the cause of the obstruction, patients may be managed 
non-operatively until obstruction resolves spontaneously, or operatively where intestinal ischaemia is suspected or spontaneous resolution is deemed unlikely. Patients undergoing a period of non-operative management may be nil by mouth for several days and patients who have operative management will sustain varying degrees of postoperative ileus. These approaches, in the context of SBO, give rise to a prolonged period without enteral nutrition in a group of patients who are already known to be at high risk of malnutrition. ${ }^{7}$

There is no specific guidance on the management of nutrition in SBO. Practice varies widely from early use of parenteral support to delayed use of nutritional interventions and current recommendations are based on low-quality evidence. ${ }^{689}$ Malnutrition is associated with poor outcomes ${ }^{10} 11$ in patients with acute illness and undergoing emergency surgery, ${ }^{10}$ which may be compounded by acute intestinal failure precipitated by SBO. It is therefore important to identify effective strategies and future areas for research to improve the nutritional management of patients with SBO.

The aim of this study was to describe the prevalence and variation of malnutrition, management and outcomes of patients with SBO.

\section{METHODS}

This national audit was conducted according to a prepublished, predefined protocol, ${ }^{12}$ and is reported in line with the STrengthening the Reporting of OBservational studies in Epidemiology and Statistical Analyses and Methods in the Published Literature guidelines. ${ }^{13} 14$

As this study was a registered national audit, using routinely collected anonymised data, formal research ethics approval was not required with confirmation by the South-East Scotland Research and Ethics committee (reference: NR/1610AB10). All sites secured local audit and Caldicott Guardian permissions to participate and were not permitted to collect data without approvals in place. The audit was registered with the Healthcare Quality Improvement Partnership (http://www.hqip.org. uk).

\section{Participants}

All UK hospitals undertaking emergency general surgery were eligible for participation in this study. Adults aged 18 years or over, admitted for suspected SBO were identified across an 8-week period from 16 January 2017 to 13 March 2017 and followed up for 30 days following discharge. A diagnosis of SBO had to be made or confirmed by a consultant or a specialty trainee with 3 or more years postgraduate surgical experience. Patients subsequently found to have non-mechanical SBO, left colonic obstruction causing SBO or who were managed with palliative intent from admission were excluded from this analysis.

\section{Collaborative network}

The National Audit of Small Bowel Obstruction was designed and delivered by trainee research collaboratives, ${ }^{15}$ with support from Royal Colleges, professional specialty associations and the Bowel Disease Research Foundation. Each site included oversight by a designated consultant surgeon, with data collection undertaken by trainee surgeons or allied health professionals. Roles of collaborators are presented in supplementary appendix A.

\section{Data, definitions and validation}

Data on route of referral to surgical team, baseline demographics (age, sex, height, weight), comorbidity (Charlson Comorbidity Index), ${ }^{16}$ admission biochemical parameters (presence of acute kidney injury, white cell count (WCC), serum albumin) were captured. The period spent nil by mouth prior to referral, and duration of any preceding hospital stay (eg, on medical ward prior to referral) was documented. Use and timing of abdominal radiography, CT scanning and administration of water-soluble contrast agents was recorded. Data on operative interventions included timing, approach and key components of the operation were captured. Nutritional data including body mass index, interval between last enteral intake and re-introduction of enteral nutrition and use of nutritional support interventions were recorded. Nutritional Risk Index (NRI) was calculated using ideal body weight, current body weight and admission albumin. ${ }^{17}$ Patients were classified in three groups according to NRI group. The three groups were defined as 'low risk' (NRI>97.5), 'moderate risk' (NRI 83.5-97.5) and 'severe risk' $(\mathrm{NRI}<83.5) .{ }^{17}$

Data were entered onto a secure REDCap database ${ }^{18}$ housed at the University of Sheffield. Records were pseudo-anonymised and only accessible to the local team and research team database administrators.

To ensure data accuracy, validation of key fields of $25 \%$ of all patient records was undertaken by an independent investigator at each site who had not been involved in primary data collection. Records were identified for sampling by using a random number generator at the coordinating site and validation completed within a predetermined 30-day time window. Categorical fields were deemed accurate when there was exact agreement between responses. Continuous variables were considered accurate with a perfect match, or $<0.5$ rounding error of reported value. Unit data were excluded if the validation process was incomplete. Data accuracy was defined as number of accurate fields per patient divided by total number of fields per patient.

\section{Public and patient involvement}

This study was conceived following a public and patient research priority setting by the Association of Coloproctology of Great Britain and Ireland. ${ }^{19}$ Throughout the study, a patient representative provided feedback and 
input on study design, attended all steering group meetings, and advised on interpretation of findings.

\section{Outcomes}

The primary outcome was time to in-hospital mortality (survival). Secondary outcomes recorded included: major complications (in-hospital mortality, reoperation, unplanned intensive care admission and 30-day readmission), complications arising from surgery (anastomotic leak, wound dehiscence), infection (pneumonia, surgical site infection, intra-abdominal infection, urinary tract infection, venous catheter infection), cardiac complications, venous thromboembolism and delirium. Case report forms and outcome definitions are available in supplementary appendix A and B, respectively.

\section{Statistical analysis}

Data were summarised using simple descriptive statistics including count and percentages for categorical variables. Continuous variables were described using the mean average for central tendency, alongside the corresponding SD. For non-parametric continuous data, median average and corresponding IQR were used. To test for differences in baseline characteristics and outcomes across nutritional risk groups, we used $\mathrm{X}^{2}$ test for categorical variables and Kruskal-Wallis or Student's t-test/Wilcoxon rank sum test for continuous variables where appropriate.

Cox proportional hazards models were used to adjust for explanatory variables at the patient level and hospital level effects (entered as a cluster term) when assessing in-hospital survival. Effects estimates for this survival analysis are presented as HRs, with corresponding 95\% CIs. To consider the effects of other explanatory variables on binary outcomes, we constructed multilevel logistic regression models to generate effect estimates for each outcome of interest. There were two levels in these models, fixed effects at the patient level which adjusted for individual patient characteristics and centre level effects were considered as random effects. Effect estimates are presented as ORs, alongside their corresponding 95\% CIs. For both the adjusted survival analysis and multilevel logistic regression, the patient level explanatory variables were entered into the model on the basis of clinical plausibility and model selection was guided by the Akaike information criterion. All first-order and second-order interactions were examined. A sample of the population over 8 weeks was planned. Using data from a 2-week pilot in eight hospitals, it was anticipated that 80 hospitals would generate a sample size of 2000 patients, which would be able to detect a difference in the primary outcome from $5 \%$ to $10 \%$, where $\beta=0.99$ and $\alpha=0.05$, with an allocation ratio of $1: 3$ across nutritional risk groups (low, moderate and severe).

To investigate the effects of parental nutrition (PN)/ total parental nutrition on outcomes in patients with SBO, we used a doubly-robust propensity score adjustment to reduce the effects of selection bias. PN use is more common in unwell patients and previous studies have shown PN use to be associated with lower survival. To assess the effects of $\mathrm{PN}$ versus comparable controls, the analysis was limited to patients with adhesive SBO. As a sensitivity analysis, we then compared the effects of early PN (defined as $<3$ days after admission) and late PN ( $>3$ days after admission) use. For both analyses, a doubly robust propensity score analysis was used. This differs from usual logistic regression modelling in that it estimates the relationship between a (non-randomly allocated) treatment and an outcome by jointly modelling a) the characteristics of patients that get the intervention and $b$ ) the characteristics that increase the risk of outcome. Doubly robust methods fit a) and b) as simultaneous estimation equations (in this case using logistic regression) before estimating the link between the intervention (PN) and outcome (death).

Finally, to compare variation across the UK in the nutritional management of SBO, funnel plots were prepared to identify outliers and variation in clinical practice. The numerator was the proportion of participants receiving the intervention at a site, divided by the total number of cases at a site (presented on the $\mathrm{X}$ axis). Mean rate of intervention and CIs were calculated and plotted.

An exploratory analysis of the relationship between WCC at admission, albumin at admission and NRI was undertaken to assess for performance in the emergency setting, using Kruskal-Wallis test.

For all hypothesis tests, the threshold for statistical significance was set at the level $\mathrm{p} \leq 0.05$. All analyses were performed in R V.3.4.4 (R Foundation for Statistical Programming, Vienna, Austria) using the tidyverse, maggitr, ggplot2, lme4, MatchIt and finalfit packages.

\section{RESULTS}

A total of 2604 patients from 131 hospitals were entered into the study. Collaborators excluded 152 patients following diagnostic test results that met the study exclusion criteria. As this analysis focusses on outcomes following treatment with curative intent, data on 73 patients who received end-of-life care have been excluded. Prior to statistical analysis, 18 patients were excluded as they did not meet the study inclusion criteria, and a further 292 patients were excluded due to missing baseline nutrition data, leaving a total of 2069 patients included in the final analysis (figure 1). The independent validation study confirmed data accuracy at $92 \%$. Missing data were uncommon as demonstrated in table 1.

\section{Patient characteristics}

In this cohort, $30.0 \%$ of patients $(622 / 2069)$ underwent surgery for SBO following a decision to operate within 24 hours of admission, $22.0 \%$ (456/2069) received an operation after an initial trial of non-operative management and 47.9\% (991/2069) were managed non-operatively (table 1). Across all patients, the mean average age was 67.0 years $(\mathrm{SD}=16.8)$, a small majority of patients were female $(54.7 \%, 1131 / 2069)$ and postoperative 


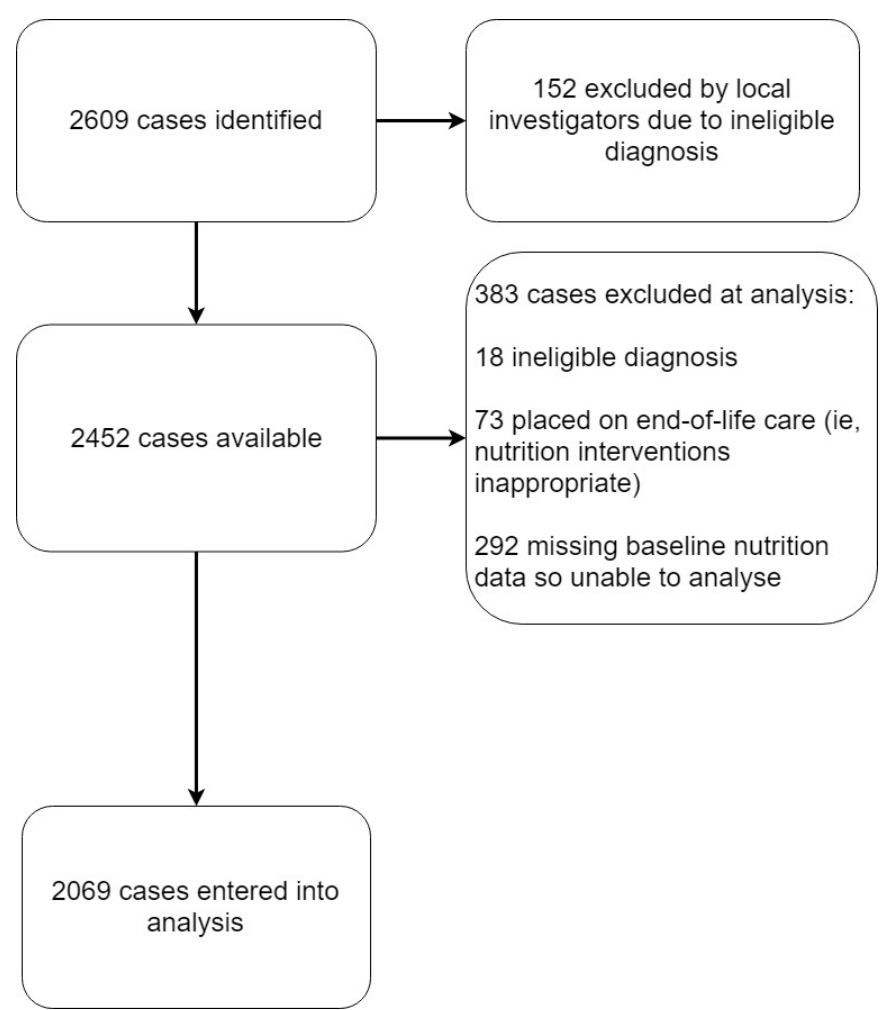

Figure 1 Patient inclusion flow chart.

adhesions were the most common cause of SBO (49.1\%, 1016/2069) (online supplementary table S1). Malnutrition was common when stratified by NRI, with $35.7 \%$ at moderate risk $(738 / 2069), 5.7 \%$ at severe risk $(118 / 2069)$ and $58.6 \%(1213 / 2069)$ at low risk of malnutrition. Patient comorbidities were comparable across NRI groups: those in the low risk NRI group had 3 Charlson Comorbidity Index points, compared with 4.2 and 3.7 points in the moderate and severe risk groups, respectively. Online supplementary table S2 describes the procedures undergone by the operative and delayed operative groups.

\section{Performance of NRI in detecting malnutrition}

The effect of inflammation on the behaviour of NRI was explored. There was overlap of mean and SD of serum albumin according to WCC (figure 2), and for NRI by WCC category (figure 3 ). There were statistically significant differences in the means of the groups, although these are not clinically meaningful; the mean serum albumin varied from 38.9 to $39.8 \mathrm{~g} / \mathrm{L}$ according to white cell count category $(\mathrm{p}=0.03)$, and the mean NRI score varied from 100.7 to 102.4 ( $\mathrm{p}=0.02)$. There was variation in the rate of use of clinical tools to assess malnutrition. As inflammatory parameters (WCC, $\mathrm{C}$ reactive protein) did not correlate with a clinically important change in NRI (see plots in supplementary figure S1), the NRI has been used to facilitate comparisons in treatment.

\section{Rates of malnutrition and detection methods}

A total of $81.6 \%(1688 / 2069)$ patients were assessed for malnutrition, either using clinical judgement or a formal screening tool (eg, Malnutrition Universal Screening Tool), and $32.8 \%(670 / 2069)$ were judged to be malnourished by their clinical team (table 2). In patients undergoing surgery, $84.6 \%(910 / 1076)$ were assessed for malnutrition compared with $78.6 \%(778 / 990)$ in the non-operative group. For patients whom the NRI identified as having a moderate risk of malnutrition, 36.4\% $(269 / 738)$ were reviewed by a dietician, with the average time to review taking 6.4 days $(\mathrm{SD}=6.5)$. For those at severe risk, this was slightly higher, with $55.9 \%$ reviewed by a dietician, with average time to review taking 4.5 days $(\mathrm{SD}=5.0)$. Patients in the low risk group had fewer reviews, with an average time around 1 week. There was substantial variation in practice in the adjusted rates of dietician review across the UK (figure 4).

\section{Supportive nutritional interventions}

Use of nutritional interventions varied across NRI groups. In the low risk group, $30.3 \%$ of patients received a nutritional intervention (oral supplements, nasogastric (NG) or nasojejunal (NJ) feeding, or PN) compared with $40.7 \%$ in the moderate risk group and $62.7 \%$ in the severe risk group. The severe and moderate risk groups had higher rates of nutritional intervention and shorter times to instituting these (table 2). Adjusted rates of PN use varied widely, with some centres using PN widely and many others where patients did not receive any (figures 4-7).

\section{Malnutrition and outcomes}

Patients who were at a severe or moderate risk of malnutrition had 4.2 and 2.4 times higher unadjusted risk, respectively, of in-hospital mortality versus those in the low risk group (table 3). Patients in the severe or moderate risk groups were also more likely to develop infections, delirium and experience and poor surgical outcomes including re-operation. When demographic and hospital variables were adjusted for in the Cox regression model, the survival of patients in comparison to the low risk group was significant worse for both the high risk (HR 2.18, 95\% CI 1.14 to $4.17, \mathrm{p}=0.018$ ) and moderate risk (HR 1.55, 95\% CI 1.01 to 2.40, $\mathrm{p}=0.046$ ) patients (table 4). For patients in the severe risk group, those who underwent surgery had a significantly lower adjusted hazard for mortality than those managed non-operatively (immediate operation HR 0.08 , 95\% CI 0.01 to 0.96 , $\mathrm{p}=0.047$; delayed operation HR $0.30,95 \%$ CI 0.08 to 1.13 , $\mathrm{p}=0.076$ ). The same was found when the moderate and severe groups were combined (immediate operation HR $0.43,95 \%$ CI 0.26 to $0.73, \mathrm{p}=0.002$; delayed operation HR $0.41,95 \%$ CI 0.25 to $0.68, \mathrm{p}<0.001)$.

Across all three NRI groups, the time to resumption of enteral intake was around 1 week (table 3 ). When adjusted for confounding factors, NRI risk group was not associated with delayed time to resumption of enteral intake (online supplementary table S3). Operative management was associated with a delay in resumption of enteral intake when compared with non-operative management (immediate operation HR 0.79 , 95\% CI 0.68 to 0.92 , 
Table 1 Patient characteristics

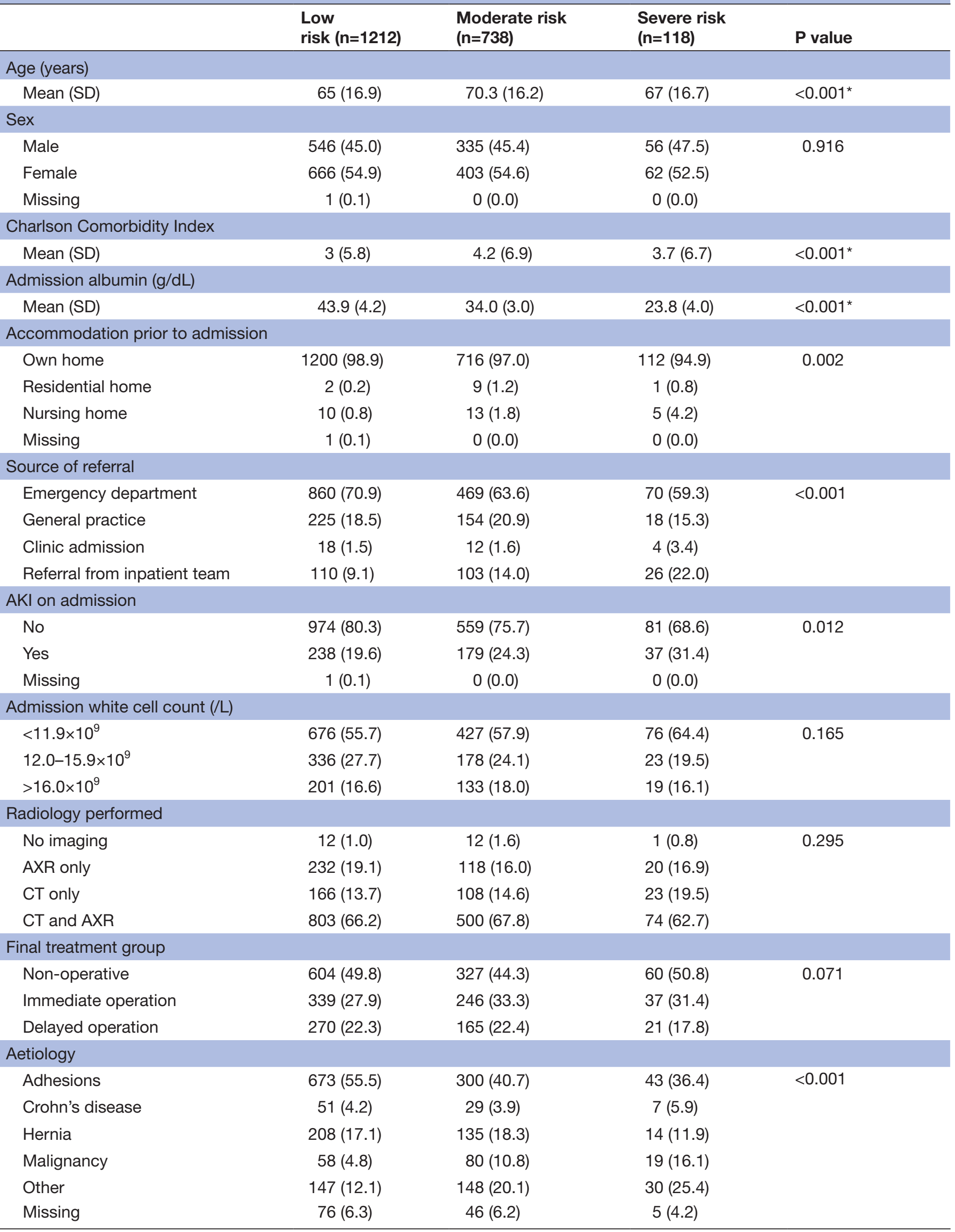


Table 1 Continued

\begin{tabular}{|c|c|c|c|c|}
\hline & $\begin{array}{l}\text { Low } \\
\text { risk }(n=1212)\end{array}$ & $\begin{array}{l}\text { Moderate risk } \\
(n=738)\end{array}$ & $\begin{array}{l}\text { Severe risk } \\
(n=118)\end{array}$ & $P$ value \\
\hline \multicolumn{5}{|l|}{ Operative approach } \\
\hline Laparoscopic converted to open & $43(3.5)$ & $29(3.9)$ & $0(0.0)$ & \multirow{4}{*}{0.186} \\
\hline Open (groin) & $42(3.5)$ & $39(5.3)$ & $2(1.7)$ & \\
\hline Open (other) & $34(2.8)$ & $22(3.0)$ & $3(2.5)$ & \\
\hline $\mathrm{N} / \mathrm{A}$ & $607(50.0)$ & $335(45.4)$ & $63(53.4)$ & \\
\hline \multicolumn{5}{|l|}{ Small bowel resection } \\
\hline No small bowel resection & $446(36.8)$ & $292(39.6)$ & $40(33.9)$ & \multirow[t]{2}{*}{0.225} \\
\hline Small bowel resection & $158(13.0)$ & $112(15.2)$ & $16(13.6)$ & \\
\hline
\end{tabular}

Stratified by NRI categories across columns.

Values are $N(\%)$ unless otherwise specified.

Tests are $\mathrm{X}^{2}$, unless otherwise indicated by asterisk $\left(^{*}\right)$, where they are Kruskal-Wallis. Albumin not tested as this comprises part of NRI. AKI, acute kidney injury; AXR, plain-film abdominal X-ray; N/A not applicable; NRI, Nutritional Risk Index.

$\mathrm{p}=0.003$; delayed operation NRI HR $0.52,95 \%$ CI 0.46 to $0.58, \mathrm{p}<0.001)$.

\section{Propensity-matched analysis for PN use}

Two analyses were performed, one for use of PN and the other for use and timing of PN. Propensity score matching produced balanced treatment groups for both analyses, with few significant differences (online supplementary table S4 and S5). The difference between groups for the use of PN was in the Charlson Comorbidity Index, where a higher score was associated with increased use. Patients who required critical care (HDU/ICU) support were more likely to receive $\mathrm{PN}$, therefore this was included in the matching algorithm. Following propensity score matching and adjustment via a doubly robust approach, PN use was not significantly associated with worse survival (adjusted HR 0.63, 95\% CI 0.25 to $1.57, \mathrm{p}=0.319$, online supplementary table S6) and there appeared to be little difference between early and late PN use (adjusted early HR $0.51,95 \%$ CI 0.11 to $2.42, p=0.397$; adjusted late

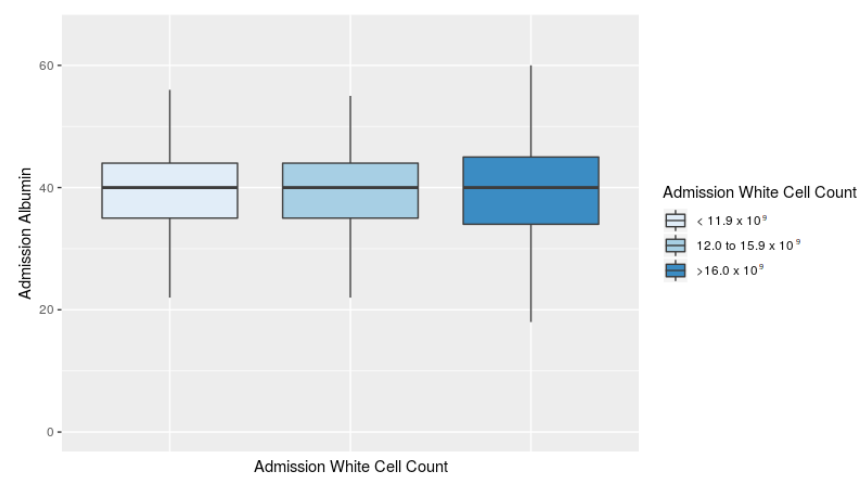

Figure 2 Relationship of admission white cell count to admission albumin.
HR $0.68,95 \%$ CI 0.25 to 1.85 , $\mathrm{p}=0.448$, online supplementary table $\mathrm{S} 7$ ). Notably, the group receiving early PN were more likely to have undergone immediate surgery, rather than delayed surgery or non-operative management.

\section{DISCUSSION}

This study identified that one-third of patients with acute SBO are at risk of malnutrition, and that malnutrition risk is significantly associated with poorer outcomes. There is wide variation in use of supportive enteral and parenteral nutrition strategies. Where it occurred, dietitian assessment of this group occurred on average 1 week after admission.

The proportion of cases of SBO due to adhesions is lower in this cohort than the $74 \%$ reported in a cohort spanning 1985-1996, whereas causes such as malignancy are more prevalent in this modern cohort. ${ }^{20}$ This change in underlying aetiology and the rates of malnutrition associated with malignancy and increasingly prevalent

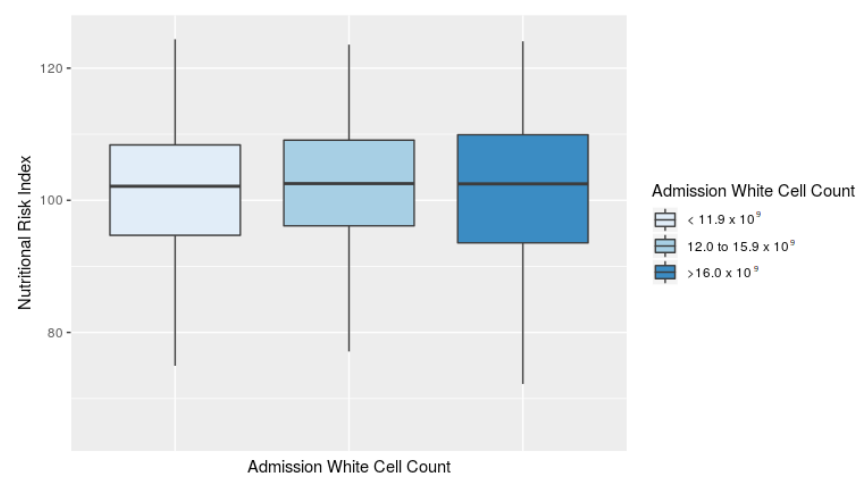

Figure 3 Relationship of admission white cell count to Nutritional Risk Index. 
Table 2 Nutritional assessment and characteristics

\begin{tabular}{|c|c|c|c|c|}
\hline & Low risk $(n=1213)$ & Moderate risk $(n=738)$ & Severe risk $(n=118)$ & $P$ value \\
\hline \multicolumn{5}{|c|}{ Was the patient identified as malnourished at any point? } \\
\hline No & $868(71.6)$ & $459(62.2)$ & $52(44.1)$ & \multirow[t]{2}{*}{$<0.001$} \\
\hline Missing & $10(0.8)$ & $1(0.1)$ & $0(0.0)$ & \\
\hline \multicolumn{5}{|c|}{ Malnutrition risk assessment } \\
\hline Missing & $1(0.1)$ & $2(0.3)$ & $0(0.0)$ & 0.345 \\
\hline \multicolumn{5}{|c|}{ Was the patient assessed using clinical judgement? } \\
\hline No & $342(28.2)$ & $206(27.9)$ & $26(22.0)$ & \multirow[t]{2}{*}{0.292} \\
\hline Yes & $597(49.2)$ & $370(50.1)$ & $67(56.8)$ & \\
\hline Yes & $785(64.7)$ & $467(63.3)$ & $78(66.1)$ & \multirow{3}{*}{0.842} \\
\hline Not assessed & $167(13.8)$ & $94(12.7)$ & $13(11.0)$ & \\
\hline Missing & $2(0.2)$ & $2(0.3)$ & $0(0.0)$ & \\
\hline \multicolumn{5}{|c|}{ Was the patient reviewed by a dietitian or nutrition team at any point during admission? } \\
\hline No & 909 (74.9) & $466(63.1)$ & $52(44.1)$ & \multirow[t]{3}{*}{$<0.001$} \\
\hline Yes & $302(24.9)$ & $269(36.4)$ & $66(55.9)$ & \\
\hline Missing & $2(0.2)$ & $3(0.4)$ & $0(0.0)$ & \\
\hline \multicolumn{5}{|c|}{ Time to review by dietician (days) } \\
\hline Mean (SD) & $7.9(22.4)$ & $6.4(6.5)$ & $4.5(5)$ & 0.001 \\
\hline \multicolumn{5}{|c|}{ Nutritional intervention } \\
\hline \multicolumn{5}{|c|}{ Were oral supplements (eg, fortisips) started at any point during admission? } \\
\hline Yes & $290(23.9)$ & $231(31.3)$ & $51(43.2)$ & \multirow{2}{*}{$<0.001$} \\
\hline Missing & $5(0.4)$ & $5(0.7)$ & $0(0.0)$ & \\
\hline \multicolumn{5}{|c|}{ Time to oral supplements (days) } \\
\hline Mean (SD) & $7.6(8)$ & $8.3(9.2)$ & $8.6(11.6)$ & 0.961 \\
\hline \multicolumn{5}{|c|}{ Was NG or NJ feed started at any point during admission? } \\
\hline No & $1157(95.4)$ & $683(92.5)$ & $101(85.6)$ & \multirow[t]{3}{*}{$<0.001$} \\
\hline Yes & $53(4.4)$ & $52(7.0)$ & $17(14.4)$ & \\
\hline Missing & $3(0.2)$ & $3(0.4)$ & $0(0.0)$ & \\
\hline \multicolumn{5}{|c|}{ Time to NG/NJ feed (days) } \\
\hline Mean (SD) & $8.8(9.1)$ & $10.9(14)$ & $24.6(58.5)$ & 0.501 \\
\hline \multicolumn{5}{|c|}{ Was TPN started at any point during the admission? } \\
\hline No & $1064(87.7)$ & $612(82.9)$ & $84(71.2)$ & \multirow[t]{3}{*}{$<0.001$} \\
\hline Yes & $147(12.1)$ & $125(16.9)$ & $34(28.8)$ & \\
\hline Missing & $2(0.2)$ & $1(0.1)$ & $0(0.0)$ & \\
\hline \multicolumn{5}{|c|}{ Time to PN/TPN (days) } \\
\hline Mean (SD) & $6.5(6.2)$ & $6.6(6.4)$ & $4.3(3.8)$ & 0.030 \\
\hline
\end{tabular}

Stratified by Nutritional Risk Index categories across columns.

Tests are $\mathrm{X}^{2}$, unless otherwise indicated by asterisk (*), where they are Kruskal-Wallis.

Values are $N(\%)$ unless otherwise specified.

NG, nasogastric; NJ, nasojejunual; PN/TPN, parenteral nutrition/total parenteral nutrition. 


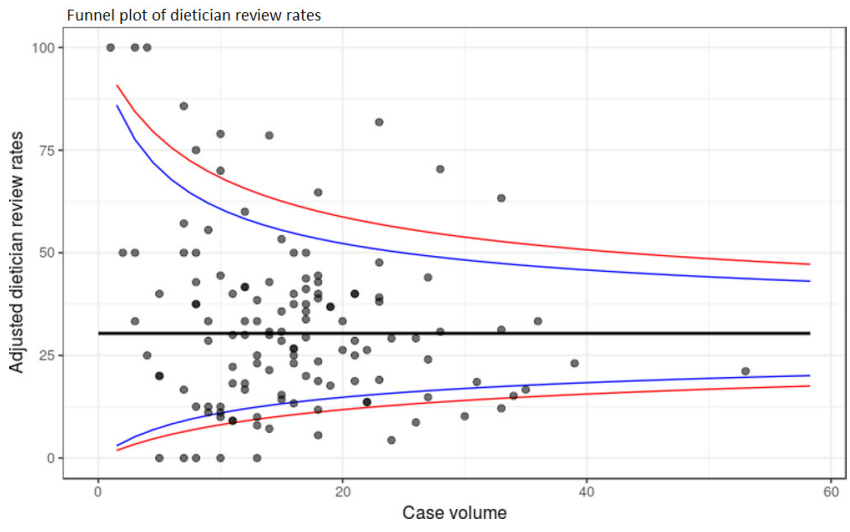

Figure 4 Dietician review rates. Red bound is $99 \% \mathrm{Cl}$ and blue bound is $95 \% \mathrm{Cl}$. Average set at the national average rate.

frailty mean that nutrition is an area which merits further attention. The National Institute for Health and Care Excellence (NICE) has provided guidelines addressing the identification and management of nutrition in surgical patients, which are applicable to this population. ${ }^{8}$ Their recommendation is that all hospital patients should be screened for malnutrition on admission and weekly thereafter. In this study, only two-thirds of patients were identified as malnourished in this way. While this may highlight problems with the accuracy of nutritional assessment on admission, it should also be recognised that the nutritional state in patients with SBO is dynamic. Patients may be nutritionally replete when admitted to hospital, but later develop nutritional problems through intestinal failure, something which is more likely to be determined on clinical grounds sometime after admission. This may explain why $28 \%$ of patients in the low risk NRI group (calculated from admission data) were subsequently judged to have malnutrition and $12 \%$ of this group ended up receiving parenteral nutrition.

NICE guidance advocates use of oral nutritional supplements in patients at risk of malnutrition, and parenteral nutrition in those without oral intake for 5 days or more. Adherence to this aspect of NICE guidance was not reflected in this study. Where patients were identified as being at risk, this did not trigger clinical actions in

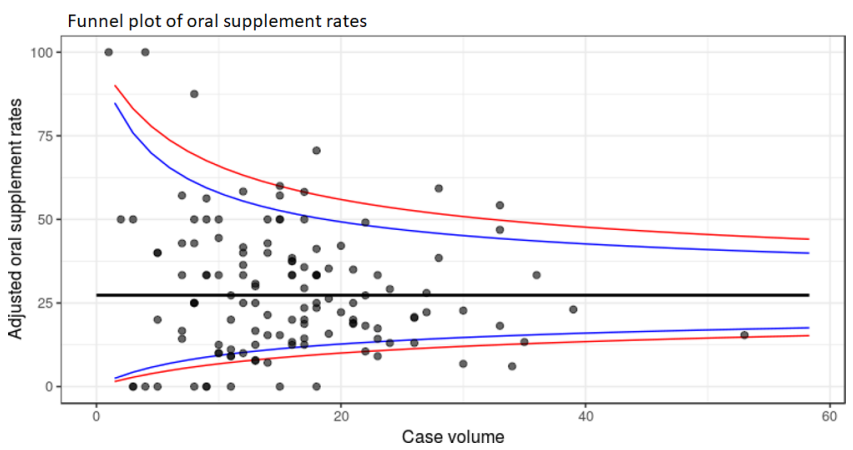

Figure 5 Use of oral supplements. Red bound is 99\% $\mathrm{Cl}$ and blue bound is $95 \% \mathrm{Cl}$. Average set at the national average rate.

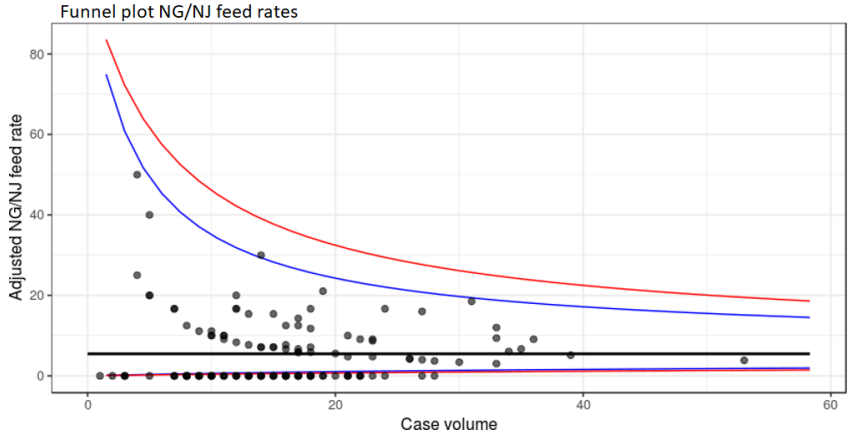

Figure 6 Use of nasogastric (NG)/nasojejunal (NJ) feed. Red bound is $99 \% \mathrm{Cl}$ and blue bound is $95 \% \mathrm{Cl}$. Average set at the national average rate.

many cases. One possibility for this discrepancy may lie in delayed access to dietitian review. Outside of critical care units, dieticians are typically the gatekeepers for nutritional interventions in UK services. Limited resource or capacity may be reflected by the low rates or absence of nutritional interventions such as NG/NJ feeding or PN in some units, suggesting 'supply sensitive' care,${ }^{21}$ although poor awareness of the impact of malnutrition on patient outcomes and the evolving nature of malnutrition in SBO may also be major contributory factors.

The finding of high rates of malnutrition is common in patients with acute illnesses. ${ }^{10}{ }^{11}$ The concern with $\mathrm{SBO}$, however, is that malnutrition is not readily correctable through conventional enteral interventions due to compromise of intestinal function. ${ }^{6}$ This puts patients at risk of malnutrition through acute illness and prevents any improvement in nutritional status due to acute gastrointestinal failure. It is well recognised that attaining adequate caloric intake is difficult in this patient population, largely due to disruption in enteral feeding and inability of a poorly functioning gastrointestinal tract to absorb sufficient nutrients. ${ }^{22}{ }^{23}$ Malnutrition could be considered a potentially modifiable risk factor to reduce mortality and prevent complications if an appropriate route of feeding can be established to overcome these issues.

Trials in the elective setting addressing preoperative or perioperative nutritional interventions in elective cancer resection populations have shown benefit over

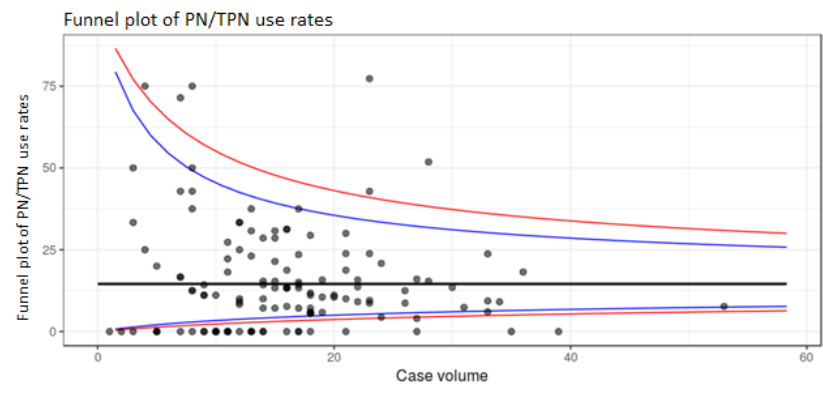

Figure 7 Parental nutrition (PN)/total parental nutrition (TPN) use rates. Red bound is $99 \% \mathrm{Cl}$ and blue bound is $95 \% \mathrm{Cl}$. Average set at the national average rate. 
Table 3 Outcomes by nutritional state

\begin{tabular}{|c|c|c|c|c|}
\hline & Low risk $(n=1213)$ & Moderate risk $(n=738)$ & Severe risk $(n=118)$ & $P$ value \\
\hline \multicolumn{5}{|l|}{ In-hospital mortality } \\
\hline No & $1164(96.0)$ & $668(90.5)$ & $98(83.1)$ & \multirow[t]{2}{*}{$<0.001$} \\
\hline Missing & $3(0.2)$ & $1(0.1)$ & $1(0.8)$ & \\
\hline \multicolumn{5}{|l|}{ Time with no enteral intake } \\
\hline$>5$ days & 439 (36.2) & $308(41.7)$ & $60(50.8)$ & \multirow{2}{*}{$<0.001$} \\
\hline Missing & $69(5.7)$ & $51(6.9)$ & $13(11.0)$ & \\
\hline \multicolumn{5}{|c|}{ Time to resumption of enteral intake } \\
\hline Mean (SD) & $7.2(14.5)$ & $7.8(9.9)$ & $8(7.4)$ & $<0.001$ \\
\hline \multicolumn{5}{|l|}{ Urinary tract infection } \\
\hline $\begin{array}{l}\text { Yes-urinary catheter } \\
\text { associated }\end{array}$ & $20(1.6)$ & $14(1.9)$ & $6(5.1)$ & \multirow{2}{*}{0.181} \\
\hline Missing & $3(0.2)$ & $4(0.5)$ & $0(0.0)$ & \\
\hline \multicolumn{5}{|c|}{ Lower respiratory tract infection } \\
\hline No & $1095(90.3)$ & $625(84.7)$ & $94(79.7)$ & \multirow[t]{3}{*}{$<0.001$} \\
\hline Yes & $115(9.5)$ & $112(15.2)$ & $24(20.3)$ & \\
\hline Missing & $3(0.2)$ & $1(0.1)$ & $0(0.0)$ & \\
\hline \multicolumn{5}{|l|}{ Deep surgical site infection } \\
\hline Missing & $2(0.2)$ & $2(0.3)$ & $0(0.0)$ & 0.645 \\
\hline \multicolumn{5}{|l|}{ Abdominal wall dehiscence } \\
\hline No & $1190(98.1)$ & $723(98.0)$ & $114(96.6)$ & \multirow[t]{3}{*}{0.577} \\
\hline Yes & $18(1.5)$ & $12(1.6)$ & $4(3.4)$ & \\
\hline Missing & $5(0.4)$ & $3(0.4)$ & $0(0.0)$ & \\
\hline \multicolumn{5}{|l|}{ Anastomotic leak } \\
\hline No & 1204 (99.3) & $726(98.4)$ & $116(98.3)$ & \multirow[t]{3}{*}{0.330} \\
\hline Yes & $7(0.6)$ & $9(1.2)$ & $2(1.7)$ & \\
\hline Missing & $2(0.2)$ & $3(0.4)$ & $0(0.0)$ & \\
\hline \multicolumn{5}{|c|}{ Radiologically guided drainage } \\
\hline No & $1196(98.6)$ & 725 (98.2) & $111(94.1)$ & \multirow[t]{3}{*}{0.002} \\
\hline Yes & $14(1.2)$ & $10(1.4)$ & $7(5.9)$ & \\
\hline Missing & $3(0.2)$ & $3(0.4)$ & $0(0.0)$ & \\
\hline \multicolumn{5}{|c|}{ Venous thromboembolism (PE or DVT) } \\
\hline No & $1200(98.9)$ & $724(98.1)$ & $113(95.8)$ & \multirow[t]{3}{*}{0.016} \\
\hline Yes & $9(0.7)$ & $11(1.5)$ & $5(4.2)$ & \\
\hline Missing & $4(0.3)$ & $3(0.4)$ & $0(0.0)$ & \\
\hline
\end{tabular}


Table 3 Continued

\begin{tabular}{|c|c|c|c|c|}
\hline & Low risk $(n=1213)$ & Moderate risk $(n=738)$ & Severe risk $(n=118)$ & $P$ value \\
\hline \multicolumn{5}{|l|}{ Delirium } \\
\hline No & $1172(96.6)$ & $690(93.5)$ & $102(86.4)$ & \multirow[t]{2}{*}{$<0.001$} \\
\hline Missing & $3(0.2)$ & $2(0.3)$ & $0(0.0)$ & \\
\hline \multicolumn{5}{|c|}{ Cardiovascular event (MI, new heart block, stroke, TIA) } \\
\hline Yes & $64(5.3)$ & $55(7.5)$ & $10(8.5)$ & \multirow{2}{*}{0.168} \\
\hline Missing & $3(0.2)$ & $4(0.5)$ & $0(0.0)$ & \\
\hline \multicolumn{5}{|l|}{ Reoperation } \\
\hline No & $582(48.0)$ & $380(51.5)$ & $52(44.1)$ & 0.027 \\
\hline No & $1111(91.6)$ & $644(87.3)$ & $94(79.7)$ & \multirow[t]{4}{*}{$<0.001$} \\
\hline Yes - intensive care unit & $50(4.1)$ & $53(7.2)$ & $17(14.4)$ & \\
\hline $\begin{array}{l}\text { Yes-high dependency } \\
\text { care }\end{array}$ & $44(3.6)$ & $36(4.9)$ & $7(5.9)$ & \\
\hline Missing & $8(0.7)$ & $5(0.7)$ & $0(0.0)$ & \\
\hline \multicolumn{5}{|l|}{ Readmission within 30 days } \\
\hline No & $1029(84.8)$ & $599(81.2)$ & $90(76.3)$ & \multirow[t]{3}{*}{0.010} \\
\hline Yes & $164(13.5)$ & $112(15.2)$ & $23(19.5)$ & \\
\hline Missing & $20(1.6)$ & $27(3.7)$ & $5(4.2)$ & \\
\hline
\end{tabular}

Stratified by Nutritional Risk Index categories across columns.

Values are $N(\%)$ unless otherwise specified. Tests are $X^{2}$, unless otherwise indicated by asterisk (*), where they are Kruskal-Wallis.

DVT, deep vein thrombosis; HDU, high dependency unit (level 2); ICU, intensive care unit/intensivetherapy unit (level 2/3); MI, myocardial

infarction; PE, pulmonary embolism; TIA, transient ischaemic attack.

no intervention in terms of reduced hospital length of stay, improved hand grip strength and reduced complications. ${ }^{17} 2425$ This effect was greatest in the most malnourished groups. ${ }^{17}$ Studies in critical care on the use of PN have not demonstrated significant survival benefit and modest improvements in quality of life or time on ventilator. ${ }^{26} 27$ However, when trial results are assessed according to outcome, it appears that PN may be associated with reduced rates of complications of care. ${ }^{28}$ The pilot TOP-UP trial has suggested a benefit to supplemental PN in the surgical population. ${ }^{29}$ These trials typically included comparison with enteral feeding in predominantly medical populations, who often have normal intestinal function and continuity. There are few studies addressing this question exclusively in the surgical population, and those targeted at the surgical population are generally of low quality and do not make clinically useful comparisons for SBO. ${ }^{30}$ While propensity-matched analyses in this study did not demonstrate any effect from the use of $\mathrm{PN}$, it is important to consider that this represents a sample of the subgroup who received PN in the study, meaning there is a high degree of selection bias. The sample is also too small with heterogeneity of aetiology to demonstrate a modest but clinically plausible difference between the two groups that has been demonstrated in other surgical studies. ${ }^{31}$

\section{Strengths and limitations}

This is a large study of real-world practice from across the UK, and benefits from the support of trainee research collaboratives and low rates of missing data. These groups have demonstrated ability to access many clinical units as well deliver quality clinical data. ${ }^{15}$ It also provides novel data on nutritional management of a large cohort of patients with a common emergency surgical condition. These real-world data can be used to generate hypotheses to guide further research based on patient-centred outcomes.

The limitations of this study are its observational nature, from which it is possible only to identify associations, not to determine causation. To examine outcomes, assessment of malnutrition was based on NRI from admissions 
Table 4 Model for survival (mortality)

\section{HR (univariable)}

Nutritional Risk Index

Low risk

Moderate risk

Severe risk

$1.81(1.24-2.65, p=0.002)$

$2.26(1.29-3.96, p=0.004)$

Final treatment group

Non-operative

Immediate operation

Delayed operation

$0.57(0.38-0.85, p=0.005)$

$0.33(0.21-0.53, p<0.001)$

$1.05(1.03-1.07, p<0.001)$

$1.05(1.03-1.06, p<0.001)$

Mean (SD)

Sex

Male

Female

$1.00(0.70-1.41, p=0.993)$

$1.09(0.73-1.63, p=0.668)$

Charlson Comorbidity Index

Mean (SD) $1.05(1.03-1.07, p<0.001)$

Admission white cell count

$<11.9 \times 10^{9}$

$12.0-15.9 \times 10^{9}$

$1.00(0.64-1.55, p=0.995)$

$>16.0 \times 10^{9}$

$1.75(1.16-2.65, p=0.008)$

$1.10(0.67-1.81, \mathrm{p}=0.698)$

$1.66(1.02-2.70, p=0.040)$

Aetiology

Adhesions

Crohn's disease

$-$

Hernia

Malignancy

Other

Was PN/TPN started at any point during the admic

No

Yes

$0.74(0.49-1.11, p=0.148)$

$1.33(0.83-2.15, p=0.237)$

AKI on admission

No

Yes

Yes

$1.67(1.17-2.39, \mathrm{p}=0.005)$

$1.67(1.17-2.39, p=0.005)$

$1.39(0.91-2.13, \mathrm{p}=0.123)$

$1.39(0.91-2.13, p=0.123)$

Initial management strategy

Non-operative

Operative (decision made within

24 hours of admission)

Source of referral

Emergency department

General practice

Clinic admission

Referral from inpatient team
$-$

$0.91(0.63-1.32, p=0.615)$

$-$

$0.86(0.54-1.38, p=0.533)$

0.00 (0.00-Infinity, $p=0.993)$

$1.04(0.66-1.62, p=0.877)$
$0.46(0.06-3.46, p=0.452)$

$2.02(1.24-3.30, p=0.005)$

$2.57(1.49-4.44, p=0.001)$

$1.00(0.59-1.69, p=0.991)$

AKI, acute kidney injury; PN, parental nutrition; TPN, total parental nutrition.

data and does not capture the dynamic aspect of repeated clinical assessments. NRI is also partly dependent on serum albumin level, which is rarely considered to be a marker of nutritional status per se. Nevertheless, hypoalbuminaemia is likely to result from sepsis and therefore to be associated with a catabolic state. It is recognised that 
duration of symptoms prior to admission correlates with worse outcomes. ${ }^{32}$ This was not directly measured in this study, rather duration of time without enteral nutrition prior to admission. The level of agreement between these two measures is not known.

\section{Explanations for findings}

NICE advocates nutritional interventions wherever malnutrition is identified, with the mode of delivery defined by disease state and time factors (eg, PN to be withheld unless period of starvation is likely to exceed 5 days). ${ }^{8}$ The most recent European Society for Clinical Nutrition and Metabolism guidelines do not offer a specific timeframe for commencement of nutritional support, although recommend early support. ${ }^{9}$ The American Society for Parenteral and Enteral Nutrition guidelines suggest nutritional interventions are withheld for a few days postoperatively, except where there is evidence of hypermetabolism or critical malnutrition. ${ }^{33}$ Each of these guidelines has a focus on nutrition in the elective surgical setting, where most of the evidence is found. The variation in recommendations from these respected bodies suggests that the underlying evidence base is not adequate to guide highly prescriptive treatment decisions on surgical patients in the emergency setting and particularly where the underlying pathology precipitates acute intestinal failure. This is likely to be reflected in the variation in practice identified in this study. ${ }^{21}$

\section{Implications for policy makers}

This study shows there is wide variation in the nutritional management of patients with SBO. Recent initiatives such as the National Emergency Laparotomy Audit have reduced variation in emergency practice. ${ }^{1}$ Policy makers should include nutritional management in routine reports of emergency surgical practice. Clinical sites should review local practices to reduce factors associated with variation in their unit, such as recording of malnutrition risk, access to dietitians and nutritional support teams. Research has not yet assessed the role of nutritional interventions, for example, early parenteral nutrition in patients with $\mathrm{SBO}^{30}$ and research in this area merits funding opportunities. Investment in hospital nutrition and dietetic services must accompany this.

Data from this study show that over half of patients with SBO are nil by mouth for $>5$ days during their hospital stay. Patients admitted to hospital in a poor nutritional state are therefore at heightened risk of developing profound malnutrition during admission. Arguably, these patients perhaps should be established on parenteral nutrition from admission, while nutritionally replete patients should receive nutrition within 5-7 days of being nil by mouth. This would be in line with NICE guidelines, and the role of PN being suggested by pilot data from the TOP-UP trial. ${ }^{29}$ Most importantly, a thorough assessment of nutritional status is required on admission, which should also establish how many days patients have gone without oral nutrition prior to being in hospital. This length of time should be factored into any recommendations for nutritional support.

\section{Implications for future research}

Funding bodies including the National Institute for Health Research and Medical Research Council have identified nutrition research as a key area for further research. Given the highlighted deficiencies in the evidence base and the variation seen here, a commissioned funding call may help identify optimum nutritional strategies in SBO.

\section{CONCLUSION}

Malnutrition is prevalent among the SBO population and is associated with poor outcomes. There is broad recognition of malnutrition in this setting, but variation in the use of nutritional interventions. This national audit has helped develop hypotheses that require testing in future research to improve outcomes for patients with SBO.

\section{Author affiliations}

${ }^{1}$ Department of General Surgery, Sheffield Teaching Hospitals NHS FT, Sheffield, South Yorkshire, UK

${ }^{2}$ General Surgery, Hull and East Yorkshire Hospitals NHS Trust, Hull, Kingston upon Hull, UK

${ }^{3}$ Department of Clinical Surgery, University of Edinburgh, Edinburgh, UK

${ }^{4}$ Nottingham University Hospitals NHS Trust, Nottingham, UK

${ }^{5}$ ScHARR, University of Sheffield, Sheffield, UK

${ }^{6}$ General Surgery, Doncaster and Bassetlaw Teaching Hospitals NHS Foundation Trust, Doncaster, UK

${ }^{7}$ Royal Wolverhampton Hospitals NHS Trust, Wolverhampton, UK

${ }^{8}$ Wirral University Teaching Hospital NHS Foundation Trust, Wirral, UK

${ }^{9}$ Colorectal Surgery, Addenbrooke's Hospital, Cambridge, Cambridgeshire, UK

Twitter@nasbo2017@wannabehawkeye @tom_drake1@cam_colorectal @ cjwwirral @Pritam_Singh @MikeBradburn2 @_deli_85

Collaborators NASBO Steering Group: John Abercrombie, Austin Acheson, Derek Alderson, lain Anderson, Simon Bach, Michael Davies, Zaed Hamady, Daniel Hind, Marianne Hollyman, Sarah Hare, Ellen Lee, John Northover, Christopher Lewis, Paul Marriott, Nick Maynard, Malcolm McFall, David Murray, Gillian Tierney, Azmina Verjee, Jonathan Wild. NASBO Collaborators: Abbott S, Abdulaal Y, Afshar S, Ah-Chuen J, Ahmed T, Akhtar M, Akram F, Aldred E, Ali A, Aly M, Amajuoyi A, Amin V, Anderson D, Anderson O, Andreou A, Ansari A, Appleton S, Ardley R, Arshad F, Ashour 0, Asour A, Athem A, Athersmith M, Ayoub F, Azeem H, Azhar B, Badenoch T, Baillie C, Bandyopadhyay D, Barker J, Barker S, Barkham B, Baron R, Barrie J, Barry-Yarrow E, Bashir G, Battersby N, Bazoua G, Behar N, Bellam S, Berger C, Bhandari S, Bhasin S, Biggs S, Bisset C, Blake L, Blencowe N, Boam T, Boddy A, Boereboom C, Bogdan M, Bogle R, Bohra P, Boland M, Bolkan H, Borg C, Boulton R, Bouras G, Boyer M, Boyle J, Branagan G, Brewer H, Briggs C, Broadhurst J, Brown E, Brown J, Brown L, Brown 0, Burns K, Butcher K, Butler M, Byrne B, Campbell L, Capper C, Cartmell M, Cash T, Chan S, Chandratreya N, Chapman J, Chapman S, Charalabopoulos A, Cheek C, Chok S, Choong W, Chow M, Chowdhury J, Coe P, Conaghan P, Conn G, Cook N, Cook T, Cooper S, Cornish J, Cotton D, Cox C, Coyne P, Crook R, Crozier J, Cuffolo G, Cunha P, Curtis N, Cutting J, Da Costa K, da Silva L, Das B, Davenport M, Davies J, Davies T, Day A, Dayal S, Dean S, Demetriou G, Dengu F, Dennis R, Dent H, Dent P, Deputy M, Devoto L, Di Benedetto G, Dindyal S, Donnelly E, Doody P, Douka E, Downham C, Dowson H, Edent H, Edgerton K, Ekpete $\mathrm{N}$, El Farran M, Elamin 0, Eljaafari M, Elsaid N, El-Sharif M, Evans J, Evans M, Ewe R, Ewing A, Exarchou K, Fallaize R, Faoury M, Farag S, Farinella E, Faulkner G, Ferguson H, Fisher 0, Fletcher J, Forouzanfar A, Foster A, Fox R, Francis N, Fretwell V, Fung D, Gammeri E, Garnham J, Geraghty A, Gilbert A, Gill C, Gill M, Gillespie M, Giordano P, Glasbey J, Goh M, Golder A, Green N, Gregoir T, Grey T, Groundwater E, Grove T, Growcott S, Gunasekaran S, Habib H, Haddow J, Halahakoon V, Halkias C, Hall C, Hampson A, Hancock L, Hanna T, Hannay J, Harikrishnan A, Harries R, Harris G, Hartley J, Harvey K, Hawkin P, Hawkins J, Healy R, Heard R, Heartshorne R, Heller S, Hendra L, Herrod P, Heywood N, Hicks G, Hobson B, Holtham S, Holtham 
S, Hope C, Hopley P, Hossain T, Hossaini S, Howse F, Hubbard T, Humphreys A, Ikram H, loannis M, Iqbal M, Iqbal N, Jain R, Jatania J, Jenkinson P, Jokhan S, Jones A, Jones C, Jones L, Joshi H, Joshi K, Joy M, Jull P, Kakaniaris G, Kakaniaris G, Kallam R, Kane E, Kang P, Kanitkar R, Kauser S, Kazmi F, Kedrzycki M, Kelly S, Kendall J, Khan M, Khan T, King G, Kisiel A, Kitsis C, Kolawole I, Korambayil S, Kosasih S, Kosti A, Kotb A, Kouris S, Kshatriya K, Kumar S, Lafaurie G, Lal R, Lau A, Lazim T, Lazim T, Lazzaro A, Lee K, Lefroy R, Leinhardt D, Leinhardt D, Lennon H, Leong K, Levy B, Lim E, Lim J, Lindley S, Liu D, Lloyd P, Locker D, Lockwood S, Lowe C, Lund J, Lunevicius R, Lunt A, Lutfi S, Luther A, Luwemba S, MahankaliRao P, Mahroof S, Mai D, Majid S, Malik A, Malik K, Mann K, Mansour S, Manu N, Mapara R, Martin C, Martin J, Martin R, Mason C, Massey L, Mathias J, Mathur P. Maude K, McArthur D, McCain S, McCluney S, Mcllroy B, McKay S, McKinley N, McNair A, McWhirter D, Mekhail P, Mellor K, Merchant J, Merker L, Messenger D, Miles A, Mir S, Mishra A, Mistry P, Miu V, Moat M, Mockford K, Mohamed E, Mohamed I, Mondragon-Pritchard M, Moore N, Moretti L, Morris H, Morrison T, Morrison-Jones V, Moss J, Moug S, Mountford D, Moynihan R, Muhammad K, Muldoon-Smith D, Mulholland J, Mullan M, Murgitroyd E, Murugaiyan K, Myers A, Mykoniatis I, Nana G, Nash T, Nassar A, Newton R, Ng C, Ng P, Ng P, Nguyen K, Nguyen K, Nicholas F, Noor M, Nowers J, Nugent C, Nunn A, Nunn R, Obeid N, 0'Callaghan J, O'Hara R, Oke 0, Olivier J, O'Neill A, O'Neill S, Osei-Bordom D, Osgood L, Panagiotopoulos S, Panchasara B, Parks R, Patel H, Patel P, Patel R, Patel S, Pawelec K, Payne C, Pearson K, Perin G, Peristerakis I, Petronio B, Phelan L, Phillips J, Pisaneschi C, Pitt J, Plunkett-Reed K, Ponchietti L, Pouzi A, Pouzi M, Powell A, Powell-Chandler A, Pranesh N, Proctor V, Pywell S, Qureshi A, Qureshi N, Rahman M, Rai Z, Ramcharan S, Rangarajan K, Rashid M, Reader H, Rehman A, Rehman S, Rengifo C, Richards E, Richardson N, Robinson A, Robinson D, Rossi B, Rutherford F, Sadien I, Saghir T, Sahnan K, Salahia G, Sarveswaran J, Saunders M, Scott B, Scott K, Seager A, Seal S, Sezen E, Shaban F, Shah P, Shah P, Shahmohammadi M, Shamsiddinova A, Shankar S, Sharpe A, Shatkar V, Sheel A, Shields T, Shinkwin M, Shurmer J, Siddika A, Siddiqui S, Simson R, Sinclair P, Singh B, Singh S, Sivaraj J, Skaife P, Skelly B, Skinner A, Slim N, Smart C, Smart N, Smith F, Smith I, Smith R, Spence G, Sreedhar A, Steinke J, Stevenson L, Stewart-Parker E, Stott M, Stubbs B, Stubbs B, Stylianides N, Subramonia S, Swinkin M, Swinscoe M, Symons N, Tahir W, Taj T, Takacs K, Tam J, Tan K, Tani S, Tanner N, Tao D, Taylor M, Thava B, Thippeswamy K, Thomas C, Thompson E, Thompson R, Thompson-Reil C, Thorn C, Tongo F, Toth G, Turnbull A, Turnbull J, Valero C, van Boxel G, Varcada M, Venn M, Ventham N, Venza M, Vimalachandran D, Virlos I, Wade T, Wafi A, Waite $\mathrm{K}$, Walker M, Walker N, Walker T, Walsh U, Wardle S, Warner R, Watfah J, Watson $\mathrm{N}$, Watt J, Watts J, Wayman J, Weegenaar C, West H, West M, Whitehurst L, Whyler M, Wiggans M, Wijeyekoon S, Williams G, Williams R, Williamson A, Williamson J, Wilson J, Winter A, Wolpert L, Wong J, Yeap E, Yeong T, Zaman S, Zappa B, Zosimas $D$, West Midlands Research Collaborative.

Contributors Study design: MJL, AES, TMD, NSF, CJW, PS, TRW, AM, MB, NASBO Steering Group. Data collection: NASBO Collaborators. Statistical analysis: MB, TMD. Preparation of manuscript: MJL, AES, TMD, NSF, CJW, PS, TRW, AM, MB. NASBO Steering Group and NASBO Collaborators have reviewed the manuscript and approved for submission.

Funding This national project was supported by the Bowel Disease Research Foundation, Association of Surgeons of Great Britain and Ireland, Association of Coloproctology of Great Britain and Ireland, Association of Upper Gastrointestinal Surgeons, British Association for Parenteral and Enteral Nutrition, British Society for Gastroenterology, Royal College of Surgeons of England, Royal College of Surgeons of Edinburgh, Royal College of Anaesthetists, British Association for Surgical Oncology, National Emergency Laparotomy Audit. Funding bodies provided financial support for administrative and statistical support, and for dissemination of materials. As all funders had dual roles as specialty associations, Royal Colleges or charities, they were invited to have representation on the steering group. Analysis, interpretation, sharing and decision to publish these findings was undertaken independently of the funding bodies.

Competing interests None declared.

Patient consent for publication Not required.

Provenance and peer review Not commissioned; externally peer reviewed.

Data sharing statement No additional data available.

Open access This is an open access article distributed in accordance with the Creative Commons Attribution Non Commercial (CC BY-NC 4.0) license, which permits others to distribute, remix, adapt, build upon this work non-commercially, and license their derivative works on different terms, provided the original work is properly cited, appropriate credit is given, any changes made indicated, and the use is non-commercial. See: http://creativecommons.org/licenses/by-nc/4.0/.

\section{REFERENCES}

1. National Emergency Laparotomy Audit. Third Report of the National Emergency Laparotomy Audit. London: Royal College of Anaesthetists, 2018.

2. GlobalSurg C. GlobalSurg Collaborative. Mortality of emergency abdominal surgery in high-, middle- and low-income countries. $\mathrm{Br} \mathrm{J}$ Surg 2016;103:971-88.

3. Jafari MD, Jafari F, Foe-Paker JE, et al. Adhesive small bowel obstruction in the united states: Has laparoscopy made an impact? Am Surg 2015;81:1028-33.

4. Symons NR, Moorthy K, Vincent CA, et al. Reliability in the process of care during emergency general surgical admission: A prospective cohort study. Int J Surg 2016;32:143-9.

5. Scott JW, Olufajo OA, Brat GA, et al. Use of national burden to define operative emergency general surgery. JAMA Surg 2016;151:e160480.

6. Vaizey CJ, Maeda Y, Barbosa E, et al. European Society of Coloproctology consensus on the surgical management of intestinal failure in adults. Colorectal Dis 2016;18:535-48.

7. Russell C, Elia M. BAPEN and collaborators. Nutrition Screening Surveys In Hospitals In England, 2007-2011: Bapen 2014.

8. National Institute for Health and Care Excellence. Nutrition support for adults: oral nutrition support, enteral tube feeding and parenteral nutrition: Clinical Guideline 32. London: NICE, 2006.

9. Weimann A, Braga M, Carli F, et al. ESPEN guideline: Clinical nutrition in surgery. Clin Nutr 2017;36:623-50.

10. Havens JM, Columbus AB, Seshadri AJ, et al. Malnutrition at intensive care unit admission predicts mortality in emergency general surgery patients. JPEN J Parenter Enteral Nutr 2018;42:014860711667659.

11. Ho JW, Wu AH, Lee MW, et al. Malnutrition risk predicts surgical outcomes in patients undergoing gastrointestinal operations: Results of a prospective study. Clin Nutr 2015;34:679-84.

12. Lee MJ, Sayers AE, Drake TM, et al. UK-based, multisite, prospective cohort study of small bowel obstruction in acute surgical services: National Audit of Small Bowel Obstruction (NASBO) protocol. BMJ Open 2017;7:e016796.

13. von Elm E, Altman DG, Egger M, et al. Strengthening the Reporting of Observational Studies in Epidemiology (STROBE) statement: guidelines for reporting observational studies. BMJ 2007;335:806-8

14. Lang T, Altman D. Basic Statistical Reporting for Articles Published in Biomedical Journals: The "Statistical Analyses and Methods in the Published Literature" or The SAMPL Guidelines". In: Smart P, Maisonneuve H, Polderman A, eds. Science Editors' Handbook: European Association of Science Editors, 2013.

15. Nepogodiev D, Chapman SJ, Kolias AG, et al. The effect of trainee research collaboratives in the UK. Lancet Gastroenterol Hepatol 2017;2:247-8.

16. Charlson ME, Pompei P, Ales KL, et al. A new method of classifying prognostic comorbidity in longitudinal studies: development and validation. J Chronic Dis 1987;40:373-83.

17. Veterans Affairs Total Parenteral Nutrition Cooperative Study Group. Perioperative total parenteral nutrition in surgical patients. $N$ Engl J Med 1991;325:525-32

18. Harris PA, Taylor R, Thielke R, et al. Research electronic data capture (REDCap)--a metadata-driven methodology and workflow process for providing translational research informatics support. J Biomed Inform 2009;42:377-81.

19. McNair AG, Heywood N, Tiernan J, et al. A national patient and public colorectal research agenda: integration of consumer perspectives in bowel disease through early consultation. Colorectal Dis 2017;19:075-085.

20. Miller G, Boman J, Shrier I, et al. Etiology of small bowel obstruction. Am J Surg 2000;180:33-6.

21. Wennberg JE, Fisher ES, Skinner JS. Geography and the debate over Medicare reform. Health Aff 2002;Suppl Web Exclusives:W96-W112.

22. Engel JM, Muhling J, Junger A, et al. Enteral nutrition practice in a surgical intensive care unit: what proportion of energy expenditure is delivered enterally? Clin Nutr 2003;22:187-92.

23. De Jonghe B, Appere-De-Vechi C, Fournier M, et al. A prospective survey of nutritional support practices in intensive care unit patients: what is prescribed? What is delivered? Crit Care Med 2001;29:8-12.

24. Braga M, Gianotti L, Nespoli L, et al. Nutritional approach in malnourished surgical patients: a prospective randomized study. Arch Surg 2002;137:174-80.

25. Keele AM, Bray MJ, Emery PW, et al. Two phase randomised controlled clinical trial of postoperative oral dietary supplements in surgical patients. Gut 1997;40:393-9. 
26. Harvey SE, Parrott F, Harrison DA, et al. Trial of the route of early nutritional support in critically ill adults. $N$ Engl J Med 2014;371:1673-84.

27. Doig GS, Simpson F, Sweetman EA, et al. Early parenteral nutrition in critically ill patients with short-term relative contraindications to early enteral nutrition: a randomized controlled trial. JAMA 2013;309:2130-8.

28. Taverny G, Lescot T, Pardo E, et al. Outcomes used in randomised controlled trials of nutrition in the critically ill: a systematic review. Critical Care 2019;23.

29. Wischmeyer PE, Hasselmann M, Kummerlen C, et al. A randomized trial of supplemental parenteral nutrition in underweight and overweight critically ill patients: the TOP-UP pilot trial. Crit Care 2017;21:142.

30. Ledgard K, Mann B, Hind D, et al. What is the evidence for the use of parenteral nutrition (PN) in critically ill surgical patients: a systematic review and meta-analysis. Tech Coloproctol 2018;22:755-66.

31. Perinel J, Mariette C, Dousset B, et al. Early enteral versus total parenteral nutrition in patients undergoing pancreaticoduodenectomy: A randomized multicenter controlled trial (Nutri-DPC). Ann Surg 2016;264:731-7.

32. Meier RP, de Saussure WO, Orci LA, et al. Clinical outcome in acute small bowel obstruction after surgical or conservative management. World J Surg 2014;38:3082-8.

33. McClave SA, Taylor BE, Martindale RG, et al. Guidelines for the Provision and Assessment of Nutrition Support Therapy in the Adult Critically III Patient: Society of Critical Care Medicine (SCCM) and American Society for Parenteral and Enteral Nutrition (A.S.P.E.N.). JPEN J Parenter Enteral Nutr 2016;40:159-211. 